\title{
Research on social desirability levels of individuals with disabilities living in the province of batman in terms of the various variables
}

\author{
H. Murat SAHIN¹, Erdal CETIN², Abdullah MANAP2, Erhan SAHIN³ \\ ${ }^{1}$ School of Physical Education and Sport, University of Batman, Batman, Turkey. \\ ${ }^{2}$ Vocational School, University of Batman, Batman, Turkey. \\ ${ }^{3}$ School of Physical Education and Sport, University of Siirt, Siirt, Turkey. \\ Address Correspondence to H. M. Sahin, hmuratsahin@gmail.com \\ This study was presented as oral presentation in $2^{\text {nd }}$ International Physical Education aand Sports Congress for the Disabled (May 2-4, 2014, \\ Batman).
}

\begin{abstract}
Generally social desirability is defined as individuals give socially desirable answers or tend to show an attitude towards a positive impression within the framework of the relations between an individual and a group, an individual and a society, which is a basic equation of social psychology. Crowne \& Marlowe tried to explain social desirability as "to imitate a good thing", "to give a culturally accepted answer" or "to give a prejudicial reaction to an approval request". Also, Edward defined it as a self-definition tendency which is socially desirable and undesirable between the scale values. In this context, this study focused on whether there were significant differences in the social desirability levels of individuals with disabilities living in the province of Batman in terms of various variables such as age, gender, monthly income, sport performance, sport performance frequency. In this study "the Two-Dimension Social Desirability Scale" which was developed by Akın, was applied to 70 people with disabilities living in Batman. The sample group of 70 people was considered to have different ages, marital status, monthly income and education level. The sample group was also asked whether they did sport or how often they did sport. According to the evaluation with the SPPS 17.0 statistical analysis program, the social desirability levels were higher in the males rather than females and in the married ones than single ones. Also, there was a significant difference between the social desirability levels and the sport performance frequencies in the individuals doing sport. It was analyzed whether the sport performance frequencies of the disabled individuals doing sport was effective on the social desirability.
\end{abstract}

Keywords: Individuals with disabilities, impression management, self-deception, social desirability.

\section{INTRODUCTION}

Social desirability is an individual's tendency to reply in a desired way by the social environment and to give reactions appropriate for the general structure of the society. While an individual with the need of being accepted by the society persists in behaviors appropriate for the social norms, acceptable and confirmable, the one reacts to emotions, opinions and behaviors not confirmed and accepted. In particular, the need of being accepted into society is a basis of these types of reactions.

Social desirability can be considered that "an individual tends to express himself in a positive way within the social norms instead of giving real information about himself when responding to the items of any measurement tool" (1). Again Edward
(7) described it as a tendency of introducing himself in the socially desired or undesired measurement values.

Social desirability is not only related to having a place in the social environment with social motives (affiliation, success, confirmation, recognition, love, etc.) considered in people, but also the assumption of social psychology that an individual's emotions, opinions and actions are affected from the existence of others (group, society). Especially people give reactions to the actions such as theft, crime, harmful habits rejected by the society as people are inclined to the actions such as mutualisation, goodness confirmed by the society. Herein the main issue is to make efforts in order to show more emotions, opinions and actions desired by the society more and these ones not accepted by the society less (2). 
The measurement of social desirability depends on the self-report measurement tools. The problem in the measurement tools based on self-report is to put more emphasis on the positive features which will affect an individual's life while responding to the items regarding an individual's attitudes, beliefs, ideas and personality as the main topic of social desirability. That is, while an individual answers the questions, he does not ignore the desire of confirmation in the social terms $(1,3)$.

There are two sub-dimensions of social desirability measurements. These are self-deception and impression management.

In Paul's $(5,7)$ words, self-deception means to emphasize about positive characteristics very often and to reject negative aspects. Here, the positive and negative characteristics have a wide variety of social, cognitive, moral abilities, etc. The dimension of deceiving himself reaches at such a progressive point that precedes the situation of being conscious. An individual deliberatively shows some performances which take him to believe these (without consciousness). Lastly, as the positive attitudes, the achievements, the accepted actions are shown to be more, the undesired aspects are reflected as if they were not available.

According to Paulhus, self-deception is an "egoist bias". On the other hand, impression management is a "moral bias". The basic issue in impression management is a desire to manage what the people around himself (others) must think about himself. The one also creates an effect on people in the current environment. And the one influences the individuals around himself to direct their impressions (social, cognitive, intellectual and moral) about him. In this regard, the situation to manipulate his own perception with the selfdeception tends to have the other people's perceptions with the impression management. Finally, an individual applies to some ways such as convincing, deceiving, manipulating with the two sub-factors during his responses $(4,5)$. The aim of the research was to reveal whether there was a relation between the social desirability levels and the other variables in the physically disabled individuals.

\section{MATERIAL \& METHOD}

The scope of the study consisted of the social desirability levels of physically disabled individuals. It was studied how the social desirability was available in the physically disabled individuals; this term called social desirability means the tendency to respond to the general morality, norms and expectations of the society. The social desirability scale was performed in the physically disabled individuals; the relevant findings were compared in the other variables of the sample group.

The scope of the research included the physically disabled individuals living in the province Batman. The sample group of 70 persons from the various ages, genders, marital status and monthly income were chosen. Also, another characteristic mentioned in the sample group was whether the physically disabled individuals were interested in sport activities. To screen sport activities, a part of the sample group consisted of the individuals doing sport.

70 persons in the research sample were applied the Social Desirability Scale developed by A. Akın (1). Akın succeeded to have the Social Desirability Scale with 2 factors of 29 items whose reliability and validity were analyzed with one study about a group of 851 students studying in Sakarya, Marmara and Anatolia University. For this research, the scale made by Akın was put into practice; the practical information was transferred to the computer via the codes. Data were solved with the SPSS 17.0 program, analyzed with t-test.

\section{RESULTS}

The significance level was given between the physically disabled individuals' genders, marital status, monthly incomes, education levels, sport performances and their social desirability levels were given in tables.

Table 1. Sample Table of Physically Disabled Individuals' Genders and Marital Status

\begin{tabular}{ccccc}
\hline & & \multicolumn{3}{c}{ Marital Status } \\
\cline { 3 - 5 } & & Married & Single & Total \\
\hline & & & & \\
& Female & 4 & 10 & 14 \\
& Male & 28 & 28 & 56 \\
& Total & 32 & 38 & 70 \\
\hline
\end{tabular}

As seen at Table 1, there were 4 married females, 10 single females, 28 married males and 28 single males in the sample group. Also, the sample group totally consisted of 70 physically disabled individuals including 32 married and 38 single ones in accordance with their marital status, 14 females and 56 males in accordance with their genders.

When examined the findings from Table 2, it was seen that there was a significant difference in the social desirability levels of the physically 
disabled individuals in accordance with their genders. As a result of the analysis, the significance level was found to be .012 ( $p>05)$. As the point average of the female participants from the social desirability scale was 99.142 , the point average of the male participants was 114.60 . The social desirability level in males was higher than the females.

Table 2. T-test results relating to the physically disabled individuals' points from the social desirability scale in accordance with genders.

\begin{tabular}{lccccc}
\hline Gender & $\mathrm{N}$ & Mean & SD & $\mathrm{t}$ & $\mathrm{p}$ \\
\hline Female & 14 & 99.142 & 17.901 & 2.567 & $.012^{*}$ \\
Male & 56 & 114.60 & 27.754 & & \\
& & & & & \\
\hline${ }^{*} \mathrm{p}<.05$ & & & & &
\end{tabular}

Table 3. T-test results relating to the physically disabled individuals' points from the social desirability scale in accordance with marital status.

\begin{tabular}{lccccc}
\hline Marital Status & $\mathrm{N}$ & Mean & SD & $\mathrm{t}$ & $\mathrm{p}$ \\
\hline Married & 32 & 120.062 & 15.127 & 3.356 & .001 \\
Single & 38 & 104.315 & 22.610 & &
\end{tabular}

${ }^{*} \mathrm{p}<.05$

As seen at Table 3, there was a significant difference in the social desirability levels of physically disabled individuals in accordance with their marital status. As a result of the analysis, the significance level was estimated to be .001 ( $p>05)$. As the point average of the married participants from the social desirability scale was 120.062 , the point average of the single participants was 104.315. The social desirability level in the married ones was higher than the single ones.

Table 4. One-way analysis results relating to the physically disabled individuals' points from the social desirability scale in accordance with education level.

\begin{tabular}{lcccc}
\hline & Sum of Squares & df & F & p \\
\hline Between Groups & 1296.676 & 3 & .983 & .406 \\
Within Groups & 29020.810 & 66 & &
\end{tabular}

Looking at the findings at Table 4, there were no significant differences in the disabled ones' social desirability levels in accordance with the education levels. According to Table 4, the significance level relating to the points from the social desirability scale in accordance with the education levels was regarded to be .406 ( $p>.05)$.

When examined the findings at Table 5, there were not any significant differences in the disabled Turk ل Sport Exe 2014; I6(3): 79-83

๑ 2014 Department of Physical Education and Sport, Selcuk University ones' income levels and social desirability levels. According to the Table 5, the significance level relating to the points from the social desirability scale in accordance with the income levels was estimated to be $.079(p>.05)$ as well.

Table 5. One-way analysis results relating to the physically disabled individuals' points from the social desirability scale in accordance with income level.

\begin{tabular}{lcccc}
\hline & Sum of Squares & df & F & p \\
\hline Between Groups & 9412.386 & 4 & 7.316 & .079 \\
Within Groups & 20905.100 & 65 & & \\
& & & &
\end{tabular}

Table 6. T-test results relating to the physically disabled individuals' points from the social desirability scale in accordance with sport performances.

\begin{tabular}{lccccc}
\hline Sport Performance & $\mathrm{N}$ & Mean & SD & $\mathrm{t}$ & $\mathrm{p}$ \\
\hline Yes & & & & & \\
No & 44 & 101.50 & 17.09 & 1.264 & .003 \\
& 26 & 114.23 & 22.67 & & \\
\hline${ }^{*} \mathrm{p}<.05$ & & & & & \\
\hline
\end{tabular}

Towards the findings at Table 6 , a significant difference was found in the physically disabled people's social desirability levels in accordance with the sport performances. The significance level was regarded to be $.003(\mathrm{p}>.05)$ in compliance with the analysis results. As the average point of the disabled individuals doing sport from the social desirability scale was 101.50, the average point of the disabled individuals not doing sport was 114.230. The social desirability level in the disabled individuals doing sport was very low.

Table 7. One-way analysis results relating to the physically disabled individuals' points from the social desirability scale in accordance with sport performance frequencies.

\begin{tabular}{|c|c|c|c|c|}
\hline & Sum of Squares & $\mathrm{df}$ & $\mathrm{F}$ & $\mathrm{p}$ \\
\hline Between Groups & 3161.822 & 3 & 2.972 & .043 \\
\hline Within Groups & 14185.178 & 40 & & \\
\hline
\end{tabular}

Looking at Table 7 , there was a significant difference in the social desirability levels in accordance with the sport performance frequencies of the disabled ones doing sport. At Table 7, the significance level relating to the points from the social desirability scale was estimated to be .043 $(p<.05)$ in accordance with the sport performance frequencies of the disabled ones doing sport. To analyze the differences between the groups, the LSD test results were given at Table 8 . 
Table 8. LSD test results relating to the physically disabled individuals' points from the social desirability scale in accordance with sport performance frequencies.

\begin{tabular}{lccccccc}
\hline $\begin{array}{l}\text { Sport Performance } \\
\text { Frequency }\end{array}$ & Every Day & 3 Days A Week & 2 Days A Week & $\begin{array}{c}\text { 1 Day A } \\
\text { Week }\end{array}$ & $\mathrm{n}$ & Mean & SD \\
\hline & & & & & & \\
Every Day & - & $\mathrm{p}>05$ & -378 & .599 & .026 & 4 & 25.50 \\
3 Days A Week & $\mathrm{p}>.05$ & $\mathrm{p}>.05$ & .652 & .029 & 18 & 27.22 & 2.041 \\
2 Days A Week & $\mathrm{p}<.05^{*}$ & $\mathrm{p}<.05^{*}$ & $\mathrm{p}<.05^{*}$ & .022 & 10 & 19.80 & 10.464 \\
1 Day A Week & & & & - & 12 & 29.66 & 0.778 \\
\end{tabular}

Looking at the items at Table 8, there were significant differences between the ones doing sport one day in a week and the ones doing sport each day at the level of .026 ( $p<.05)$; between the ones doing sport one day in a week and the ones doing sport two days in a week at the level of .022 ( $\mathrm{p}<.05)$; between the ones doing sport one day in a week and the ones doing sport three days in a week at the level of $.029(p<.05)$. Also, there were no significant differences in the social desirability levels between the physically disabled individuals doing sport each day and the ones doing sport two days and three days in a week, between the ones doing sport two days in a week and the ones doing sport three days in a week.

\section{DISCUSSION}

Even though the researches related with the social desirability are much more and old all over the world, these ones about this issue are only very limited with a few master studies in Turkey. In this regard, it is exactly restricted to compare the relevant study with other researches.

Totally 70 physically disabled individuals including 14 females, 56 males from the different age groups were applied the social desirability scale. A significant difference was found between the gender and the social desirability level. According to data, the males' social desirability levels were higher than the females. The tendency of responding to the social norms, the generally accepted ones and the environmental demands was more in the males. Hereby, one recent study (7) about the managers had similar results in "impression management" as a sub-dimension of social desirability.

When evaluated in the genders (32 married, 38 single), the married ones' social desirability levels were higher than the single ones. This situation proves that the need of being accepted and confirmed in the society is clearer in the married individuals. The married individuals give much more importance to conservationism rather than the single ones, which can be related with the importance given to other impressions about themselves. Similarly, the single individuals do not completely feel the social pressure which affects the individual preferences in ideas, behaviors and emotions; this plays an important role in this situation as well.

Some researchers showed that the social desirability level was higher in the individuals with the high education level. These individuals are more aware of which reactions are approved by the society, which is an important factor (1). But any significant differences were not observed between the education levels and the social desirability levels of the physically disabled individuals in the relevant study.

The other variable was income level. Any significant differences were not found in the income levels and the social desirability levels of the physically disabled individuals.

Another variable was also if the disabled individuals did sport or not. The issue whether sport affects the social desirability level has become the vital sub-titles mentioned in this study. In particular, the disabled individuals who had habits for doing sport or did sport professionally or unprofessionally were included in the sample group as well. In the sample group of 70 persons, 40 persons regularly did sport, 24 ones said that they did not do any sport. As a result of the study, a significant difference was found in the two variables (sport performance and social desirability). The point average of social desirability in the disabled individuals not doing sport was higher than the disabled ones doing sport. Especially it can be said that the individuals who are interested in sport and achieve in this field, are more self-confident. The need of being approved by the society becomes low in the individuals who increased self-confidence due to their achievements.

Furthermore, it was analyzed whether the sport performance frequencies of the disabled individuals doing sport was effective on the social desirability. A significant difference was seen between the social desirability levels of the professional athletes stating 
that they did sport a day in a week and the social desirability levels of the disabled individuals stating that they did sport each day, two days and three days in a week. The social desirability level in the disabled individuals stating that they did sport a day in a week was higher.

\section{REFERENCES}

1. Akın A. Two Dimensional social desirability scale: The study of validity and reliability. Gazi University Journal of Education Faculty, 2010; 30(3); 771-784.

2. Alp Z. Çalışanların ve emeklilerin sosyal istenirlik ve özduyarlılık açısından karşılaştırılması. Marmara University, social Sciences Institute, Master Thesis, 2012; 15.
3. Crowne DP, Marlowe D. A new scale of social desirability independent of psychopathology. Journal of Consulting Psychology, 1960; 24: 349-354.

4. Dodaj A. Social desirability and self-reports: testing content and response-style model of socially desirable responding. Europe's Journal of Psychology, 8(4), 651-666, 2012.

5. Paulhus DL, John OP. Egoistic and moralistic biases in selfperception: The interplay of self-deceptive styles with basic traits and motives. Journal of Personality, 1998; 66: 1025-1060.

6. Paulhus DL. Two components of socially desirable responding. Journal of Personality and Social Psychology, 1984; 46: 598-609.

7. Sağlam A. Çalışanların ve yöneticilerin sosyal istenirlik ve özgünlük düzeylerinin karşılaştırılması. Marmara University, social Sciences Institute, Master Thesis, 2012; 12-15. 